\title{
The Effect of Different Repeated Doses of Cypermethrin on the Behavioral and Histological Alterations in the Brain of Rabbits (Oryctolagus cuniculi)
}

\author{
Latif Ahmad ${ }^{1,2}$, Shafia Tehseen Gul ${ }^{1}$, M. Kashif Saleemi ${ }^{1}$, Riaz Hussain ${ }^{3}$, Aziz ur Rehman ${ }^{1,4}$, Syed \\ Naimul Hassan Naqvi ${ }^{5}$, Xiaoxia Du ${ }^{6, *}$ and Ahrar Khan ${ }^{1,6, *}$ \\ ${ }^{1}$ Faculty of Veterinary Science, University of Agriculture, Faisalabad-38040, Pakistan \\ ${ }^{2}$ Baqai College of Veterinary Sciences, Baqai University, Karachi-75340, Pakistan \\ ${ }^{3}$ Department of Pathology, Faculty of Veterinary and Animal Sciences, The Islamia University Bahawalpur, Pakistan \\ ${ }^{4}$ College of Veterinary and Animal Sciences Jhang, University of Veterinary and Animal Sciences, Lahore-54000, Pakistan \\ ${ }^{5}$ Baqai Pharmaceutical Institute, Baqai Medical University, Karachi-75340, Pakistan \\ ${ }^{6}$ Shandong Vocational Animal Science and Veterinary College, 88 Eastern Shengli Street, Weifang 261061, China. \\ *Corresponding author: duxiaoxia0931@126.com (XXD), ahrar1122@yahoo.com (AK)
}

\begin{abstract}
Article History: 21-368 Received: 09-Aug-21 $\quad$ Revised: 19-Aug-21 $\quad$ Accepted: 04-Sep-21
\section{ABSTRACT}

Among pesticides, insecticides are being used to control external parasitic infestations in animals and crops and combat vermin in and around houses. Insecticides are associated with harmful effects on body organs, including brain damage. To explore the toxic effects of pyrethroid insecticides on the brain, this study was conducted to explore the neuraltoxicological effects of cypermethrin (CY) in apparently healthy adults and weight-matched male rabbits $(n=40)$. Different doses $\left(0,50,100\right.$, and $150 \mathrm{mg} \mathrm{kg}^{-1}$ body weight $)$ of CY mixed in mustard oil were injected intraperitoneally at weekly intervals for 71 days in rabbits assigned into four equal groups: W, X, Y, and Z. The rabbits under experiment were monitored daily for various clinical signs of toxicity and fodder intake, whereas the body weight was noted weekly. Two rabbits from each group were euthanized fortnightly, and the brain from each animal was collected for morphological and histological examination. The CY-treated rabbits showed various clinical signs, decreased body weight gain, and reduced relative brain weight. Microscopically, the CY-treated rabbits showed Purkinje neurons of the cerebellum and pyramidal neurons of the cerebral cortex at different stages of development. Therefore, CY could lead to brain and behavior alterations in rabbits and increase the risk of diseases.
\end{abstract}

Key words: Oryctolagus cuniculi, Pesticides, nervous signs, Neurotoxicology

C202I IJVS - All Rights Reserved

\section{INTRODUCTION}

Pesticides are chemicals generally known to kill pests. Pesticides are indispensable in agricultural production (Tudi et al. 2021). Farmers have been using them to control weeds and insects, and their remarkable increases in agricultural products have been reported (Özkara et al. 2016; Akram et al. 2021). These are classified by different targets of pests, including fungicides, insecticides, herbicides, and rodenticides (Tudi et al. 2021). For example, fungicides are used to kill fungi, insecticides are used to kill insects, while herbicides are used to kill weeds (Mnif et al. 2011; Amaral 2014). Based on chemical composition, these are classified into organic and inorganic pesticides such as ferrous sulfate, copper, copper sulfate, sulfur, and lime. Organic pesticides are complicated (Kim et al. 2017) and classified according to their chemical structure. Major classes are insecticides, herbicides, nematocides, and rodenticides. Insecticides include carbamate, organophosphorus, chlorohydrocarbon and synthetic pyrethroids. Whereas herbicides include synthetic urea, triazine, metabolite, and hormone analog herbicides. Nematocides and rodenticides include benzimidazole nematocides, metal phosphide rodenticides, metaldehyde molluscicides and D group vitamin-based rodenticides (Tudi et al. 2021). According to Fig. 1 Zhang et al. (2018), most of the abundant pesticides being used for agricultural purposes are organophosphorus (34\%) followed by herbicides $(26 \%)$, organonitrogen $(17 \%)$, pyrethroids $(2 \%)$ and other classes $(10 \%)$. Herbicides are comprised of glyphosate $(52 \%)$ and non-glyphosate $(48 \%)$.

Cite This Article as: Ahmad L, Gul ST, Saleemi MK, Hussain R, Rehman AU, Naqvi SNH, Du XX and Khan A, 2021. The effect of different repeated doses of cypermethrin on the behavioral and histological alterations in the brain of rabbits (Oryctolagus cuniculi). International Journal of Veterinary Science 10(4): 347-354. https://doi.org/10.47278/ journal.ijvs/2021.092 
Among pesticides, insecticides can control external parasitic infestations in animals and crops and combat vermin in and around houses (Ghaffar et al. 2020). Increased use of insecticides is becoming the major means of resisting insect-borne diseases since the early $20^{\text {th }}$ century (Gul et al. 2020). Insecticides are associated with harmful effects on body organs, including wide-ranging brain damage. The insecticides reflect their neurotoxic effects mostly by gliosis, vague changes of glial tissues to central nervous system (CNS) injuries such as reported multiple system atrophy, prion disease, and multiple sclerosis (Igho and Afoke 2014; Ren et al. 2021). These discoveries were similar to investigations in which cerebellar and cerebral changes occurred due to insecticide treatment in rats (Gupta 2012).

The dermal and respiratory routes of pesticide exposure are most important in animals as well as humans. The use of personal protective equipment becomes inapplicable due to price, accessibility, perfunctory and thermic issues (Garrigou et al. 2020). The most frequently reported symptom of occupational exposure to pesticides is paresthesia in humans. Systemic signs of such poisoning include cramps in limbs, faintness, headache, unusual tiredness, queasiness, stomach discomfort, chest tightness, cough, nose and throat touchiness, eye irritation, and tearing (Khaki et al. 2017). The pyrethroid insecticides (e.g., ecofleece, a cypermethrin (CY) preparation) are commonly used and relatively safe pesticides (Ahmad et al. 2012; Hegab et al. 2020). The most obvious signs related to overdose of the pyrethroids in animals are the general malaise and weakness, accompanied by digestive and CNS disturbances. Motor nerve senses are the most extensively described neuro-behavioral endpoint of pyrethroid poisoning in mammals, independent of the route of entry or species (Rajawat et al. 2019). Such poisoning causes reduced feed intake, hypersalivation, choreoathetosis, severe athetosis, ataxia, staggering gait, muscular weakness, and tremors, licking of different body parts, depression, swaying gait, and prostration (Sallam et al. 2015; Tahir et al. 2021). Choreoathetosis is copious ptyalism with coarse tremors and bending and twisting motion after augmented pawing and burrowing (Rajawat et al. 2019). Skin irritation, itching, scratching, hyperexcitability, increased startle response and increased number and frequency of bursts of paroxysmal epileptic activity with tonic-clonic seizures affecting the whole body of CY-treated animals have also been reported (Khan et al. 2009). All these altered responses point to change brain functionality with CY.

Pyrethroids are extensively used in agriculture, animal farming, leather trade and manufacturing, and household activities (Gupta 2012; Mujahid et al. 2021). Numerous workers have been reporting the results of the studies conducted in rabbits specifically be correlated to many of clinical investigations and in vitro studies for humans. Rabbit is likewise a reproducible model for investigating the effects of toxins in vivo (Nielsen et al. 2018).

Therefore, rabbits (Oryctolagus cuniculi) were carefully chosen in this research for evaluating CY neurotoxicity. The repeated treatments of CY at weekly intervals as used in this study match with the routine insecticidal sprays/treatments to crops and animals, usually overdosing the recommended level (Gupta 2012). The 71- days' time duration was used in this study in view of 60-80 days of the gametogenic cycle for the male rabbits (Ecobichon 1996). The gametogenic cycle is important as the hypothalamic-pituitary-gonadal axis is specifically involved in pyrethroid pathogenesis (Ye and Liu 2019). The current toxicity database on general toxico-pathology by pyrethroids especially regarding the relation of brain and behavior in animals is scarce. Thus, the present study was executed for evaluating CY neurotoxicity in rabbits.

\section{MATERIALS AND METHODS}

\section{Approval of Bioethics Committee}

All the methods were allowed in this study by The Bioethics Committee, University of Agriculture Faisalabad, Pakistan. All experiments were performed according to the relevant guidelines and regulations. This document was generated in accordance with the advice of Animal Research: Reporting of in vivo Experiments (ARRIVE), the ARRIVE guidelines 2.0 (Percie du Sert et al. 2020).

\section{Experimental Design}

Apparent healthy, 6 months old 40 male rabbits with average weight $(990 \pm 50 \mathrm{~g})$ were procured from the local market and reared as briefly described here. Separate cages with dimensions $35 \times 35 \times 25 \mathrm{~cm}$ were thoroughly cleaned and displaced randomly in air-cooled animal houses. Rabbits were daily monitored and offered a weighted amount of fresh Berseem fodder/Egyptian clover (Trifolium alexandrinum). The remaining fodder was estimated to calculate animal's consumption before adding the next fodder. Clean drinking water was provided ad libitum. The room temperature for animals was set at 25 $27^{\circ} \mathrm{C}$ with $45-70 \%$ humidity and 12-h light-dark cycle during the whole experiment (Ahmad et al. 2012).

The CY (92\%) used in the study was supplied by M/S Pak-China Chemicals, Lahore, Pakistan. The CY was mixed in mustard oil as CY has good solubility in it (Gupta 2012). The required injectable dose of CY body weight (bwt) was adjusted. After 5 days of acclimatization, rabbits $(n=40)$ were randomly distributed into four equal groups, i.e., groups W, X, Y and Z. Oral LD 50 of CY is $2400 \mathrm{mg} . \mathrm{kg}$ 1 bwt in rabbits (Hartley and Kidd 1990). The $1 / 48^{\text {th }}$ (50mg.kg ${ }^{-1}$ bwt), $1 / 24^{\text {th }}\left(100 \mathrm{mg} \cdot \mathrm{kg}^{-1} \mathrm{bwt}\right)$, and $1 / 16^{\text {th }}$ (150mg. $\mathrm{kg}^{-1} \mathrm{bwt}$ ) of it were injected intraperitoneally i.e. groups $\mathrm{W}, \mathrm{X}, \mathrm{Y}$, and $\mathrm{Z}$ received nil $\left(0 \mathrm{mg} . \mathrm{kg}^{-1} \mathrm{bwt}\right)$, low (50mg.kg- bwt), medium (100mg.kg ${ }^{-1}$ bwt), and high (150mg. $\mathrm{kg}^{-1} \mathrm{bwt}$ ) CY doses, respectively at weekly interval up to experimental day 71 .

\section{The Studied Parameters}

For 71 days, fodder consumption and various clinical signs of toxicity were observed and recorded twice daily. The clinical signs score was (---- to ++++) according to the severity of the observed signs, while the body mass of each animal was recorded weekly. Two rabbits were randomly picked from each group, euthanized fortnightly (at days 15 , $29,43,57$, and 71 of observation period), and the brain from each animal was excised to record brain's weight and any gross change. The relative weight of the brain of each rabbit was calculated.

The coronal trimming of the whole brain of each rabbit into 3-mm-thick slices was performed and then processed 
by the routine method of dehydration and paraffin embedding for histopathology. Sections of $4-5 \mu \mathrm{m}$ thickness of the cerebellum and cerebrum were cut and stained with hematoxylin and eosin (Suvarna et al. 2018). A semi-quantitative assessment based on arbitrary scores (--- to ++++) was carried out regarding histological changes. From this semi-quantitative measure, a cumulative score was derived for the overall severity of histological change in a particular group.

\section{Statistical Analysis}

The collected data were analyzed statistically. The randomized complete block design was used, and means were compared by applying analysis of variance using Minitab statistical software package on a personal computer. The significance level was considered as $\mathrm{P}<0.05$.

\section{RESULTS}

\section{Physico-Clinical Parameters}

Any clinical signs and behavioral alterations did not develop in rabbits of group $\mathrm{W}$ (control) throughout the experiment. The severity of clinical signs in the CY-treated rabbits was dose-related. Rabbits in all CY-treated groups showed skin irritation, coarse tremors, dullness, lacrimation, low body temperature, dilated pupils, increased eyeball movement, breathlessness, pawing, burrowing, and ptyalism (Table 1). These effects were more obvious between $15 \mathrm{~min}$ and $1.5 \mathrm{~h}$ after each injection and disappeared within 12-24 hours in all animals. One rabbit belonging to group-Y (100mg. $\left.\mathrm{kg}^{-1} \mathrm{bwt}\right)$ died after the sixth CY treatment. A significant $(\mathrm{P} \leq 0.05)$ decrease in average fodder intake was observed in the treated groups in a dose-dependent manner (Table 2).

The body weight in the control and treated groups was non-significantly varied at zero and $1^{\text {st }}$ day of observation. The body weight gain started decreasing in the treated rabbits compared to control from the eighth day of the experiment. The body weight was significantly $(\mathrm{P} \leq 0.05)$ reduced in medium (100mg. $\left.\mathrm{kg}^{-1} \mathrm{bwt}\right)$ and high $\left(150 \mathrm{mg} \cdot \mathrm{kg}^{-}\right.$ ${ }^{1}$ bwt) dose groups on days 15-71 of observation (Table 3). In rabbits treated with the low dose $\left(50 \mathrm{mg} \cdot \mathrm{kg}^{-1} \mathrm{bwt}\right)$ the body weight remained significantly low during days 8-50 of the observation (Table 3). Relative weights of brains were significantly $(\mathrm{P} \leq 0.05)$ decreased in all treated groups at day 57, but at day 43 in group Y that treated with medium dose (100mg.kg ${ }^{-1}$ bwt) of CY (Table 4).

Table 1: Frequency and incidence of clinical signs in male rabbits injected with different doses of cypermethrin

\begin{tabular}{|c|c|c|c|c|c|c|}
\hline \multirow[b]{3}{*}{ Clinical signs } & \multicolumn{6}{|c|}{ Group (CY dose: $\left.\mathrm{mg} \cdot \mathrm{kg}^{-1} \mathrm{bwt}\right)$} \\
\hline & \multicolumn{2}{|c|}{$X(50)$} & \multicolumn{2}{|c|}{ Y (100) } & \multicolumn{2}{|c|}{$\mathrm{Z}(150)$} \\
\hline & $\overline{\mathrm{F}^{*}}$ & $\mathrm{I}^{* *}$ & $\mathrm{~F}$ & I & $\mathrm{F}$ & $\mathrm{I}$ \\
\hline Skin irritation & ++-- & 50 & +++- & 70 & ++++ & 0 \\
\hline & ++-- & 20 & +++- & 30 & ++++ & 50 \\
\hline & ++-- & 40 & +++- & 60 & ++++ & 70 \\
\hline LU & ++-- & 50 & +++- & 50 & ++++ & 80 \\
\hline & ++-- & 60 & ++++ & 70 & ++++ & 80 \\
\hline D1 & +--- & 30 & +++- & & ++++ & \\
\hline & ++-- & 30 & +++- & & ++++ & 60 \\
\hline & ++-- & 30 & +++- & & ++++ & \\
\hline & +++- & 60 & ++++ & & ++++ & 100 \\
\hline Tyansmi/sanvation & ++-- & 50 & ++- & 00 & ++++ & 80 \\
\hline \multicolumn{7}{|c|}{$\begin{array}{l}\text { *F=Frequency; } * * I=\text { Incidence (percentage). } \\
\text { concentrations of cypermethrin mixed in mustard oil were } \\
\text { injected intraperitoneally in male rabbits }(\mathrm{n}=40) \text { at weekly } \\
\text { intervals. Animals were monitored twice daily for clinical signs. } \\
\text { Different clinical signs in each animal were scored based on } \\
\text { severity (---- to ++++). The control group (W) did not exhibit any } \\
\text { clinical signs. -=No clinical signs; +=Mild clinical signs; } \\
++=\text { Moderate clinical signs; +++=Severe clinical signs and } \\
++++=\text { Very severe clinical signs. }\end{array}$} \\
\hline
\end{tabular}

\section{Histological Alterations}

The present study showed neither gross change in the brain of CY-treated rabbits nor microscopic alterations in the control group. However, a certain degree of cerebral hemorrhages and changed appearance of Purkinje and pyramidal neurons in CY-treated groups were observed histologically (Table 5). The histological alterations included different stages of neuronal development including degenerated pyramidal neurons of the cerebral cortex (Fig. $2 \mathrm{a}$ and $2 \mathrm{~b}$ ) and degeneration of Purkinje neurons of the cerebellum (Fig. 3). However, when certain dose levels of a pyrethroid produce prolonged and severe motor signs, the same induce axonal degeneration in peripheral nerves. This effect of pyrethroid is reversible in 7 days.

\section{DISCUSSION}

\section{Physico-Clinical Parameters}

In the present study, the severity of clinical signs in the CY-treated rabbits was dose-related and the main clinical

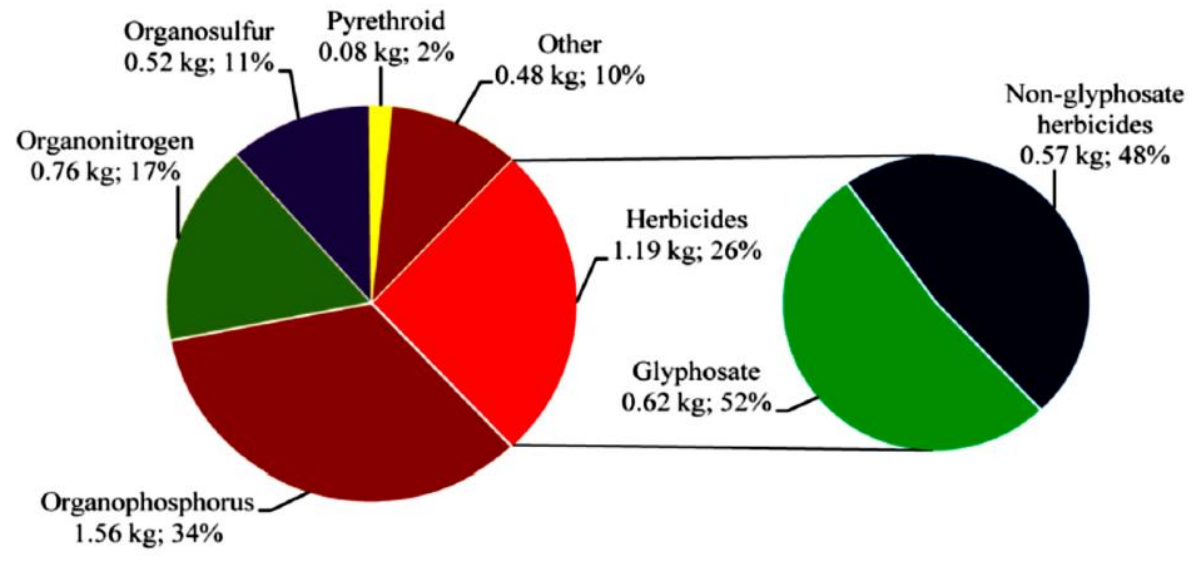

Fig. 1: Classes of agricultural pesticides being used (Zhang et al. 2018). 
Int J Vet Sci, 2021, 10(4): 347-354.
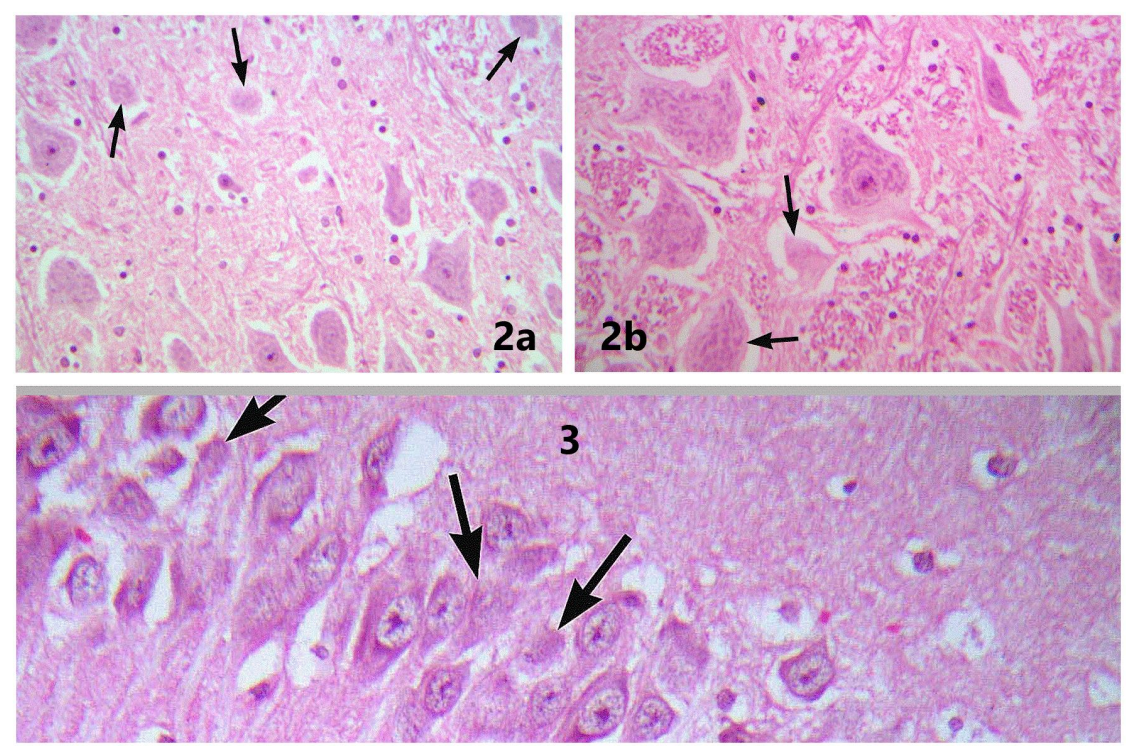

Fig. 2a: Photomicrograph of the cerebral cortex at experimental day 71 of rabbit's treatment with medium (100mg. $\mathrm{kg}^{-1} \mathrm{bwt}$ ) dose of cypermethrin (CY) showing under developing (immature) pyramidal cells (arrows). Fig. 2b: Photomicrograph of the cerebral cortex at experimental day 71 of rabbit treated with high (150mg.kg-1 bwt) dose of CY showing under developing pyramidal cells (arrows).

Fig. 3: Photomicrograph of the cerebellum at day 71 of rabbit treated weekly with CY (150mg.kg-1 bwt), showing under developing Purkinje cells. $\mathrm{H}$ and $\mathrm{E}$. 400X.

Table 2: Average fodder intake $(\mathrm{g})$ in rabbits inoculated with different cypermethrin doses Experiment week

Groups (CY dose: $\mathrm{mg} \mathrm{kg}^{-1} \mathrm{bwt}$ )

\begin{tabular}{|c|c|c|c|c|}
\hline \multicolumn{4}{|c|}{ Groups (CY dose: $\mathrm{mg} \cdot \mathrm{kg}^{-1}$ bwt) } & \multirow[t]{2}{*}{ P-Value } \\
\hline $\mathrm{W}(0)$ & $\mathrm{X}(50)$ & $Y(100)$ & $\mathrm{Z}(150)$ & \\
\hline $64.52 \pm 3.00$ & $67.38 \pm 2.52$ & $67.38 \pm 2.86$ & $67.14 \pm 2.67$ & 0.179 \\
\hline $73.10 \pm 2.24$ & $71.91 \pm 4.56$ & $75.71 \pm 2.86$ & $71.67 \pm 2.72$ & 0.100 \\
\hline $81.91 \pm 3.66$ & $80.00 \pm 1.36$ & $78.57 \pm 3.53$ & $73.57 \pm 1.8^{*}$ & 0.000 \\
\hline $91.67 \pm 2.15$ & $82.14 \pm 1.3^{*}$ & $78.81 \pm 1.9 *$ & $72.86 \pm 1.9^{*}$ & 0.000 \\
\hline $92.57 \pm 1.51$ & $81.71 \pm 3.2^{*}$ & $80.29 \pm 2.7 *$ & $72.29 \pm 2.7 *$ & 0.000 \\
\hline $93.43 \pm 0.98$ & $88.00 \pm 2.0^{*}$ & $83.14 \pm 2.0 *$ & $81.14 \pm 2.0^{*}$ & 0.000 \\
\hline $96.43 \pm 2.44$ & $86.07 \pm 2.4 *$ & $80.71 \pm 2.8^{*}$ & $78.57 \pm 1.0^{*}$ & 0.000 \\
\hline $97.14 \pm 0.95$ & $86.43 \pm 2.8^{*}$ & $81.43 \pm 2.8^{*}$ & $76.79 \pm 1.9^{*}$ & 0.000 \\
\hline $98.57 \pm 1.78$ & $82.38 \pm 4.6^{*}$ & $78.10 \pm 4.2 *$ & $74.29 \pm 4.2^{*}$ & 0.000 \\
\hline $103.33 \pm 2.72$ & $87.14 \pm 4.5^{*}$ & $81.90 \pm 3.3 *$ & $77.62 \pm 4.6^{*}$ & 0.000 \\
\hline $114.29 \pm 3.45$ & $99.29 \pm 3.5^{*}$ & $92.86 \pm 2.7 *$ & $85.71 \pm 3.5^{*}$ & 0.000 \\
\hline $119.38 \pm 4.96$ & $103.13 \pm 5.3 *$ & $98.75 \pm 5.2 *$ & $93.75 \pm 5.2 *$ & 0.000 \\
\hline
\end{tabular}

Various concentrations of CY mixed in mustard oil were injected intraperitoneal to the male rabbits $(\mathrm{n}=10 \mathrm{x} 4)$ at weekly intervals. The values (mean $\pm \mathrm{SD})$ bearing asterisk in a row differ significantly $(\mathrm{P} \leq 0.05)$.

Table 3: Body weight ( $\mathrm{g}$ ) of male rabbits injected with different doses of cypermethrin

\begin{tabular}{|c|c|c|c|c|c|}
\hline \multirow{2}{*}{ Experiment Day } & \multicolumn{4}{|c|}{ Groups (CY dose: $\mathrm{mg} \cdot \mathrm{kg}^{-1} \mathrm{bwt}$ ) } & \multirow{2}{*}{ P-Value } \\
\hline & $\mathrm{W}(0)$ & $\mathrm{X}(50)$ & $\mathrm{Y}(100)$ & $\mathrm{Z}(150)$ & \\
\hline 0 & $1011 \pm 39.6$ & $1021 \pm 35.5$ & $1025 \pm 22.4$ & $1026 \pm 32.7$ & 0.735 \\
\hline 1 & $1150 \pm 39.5$ & $1145 \pm 34.7$ & $1165 \pm 22.4$ & $1155 \pm 32.1$ & 0.544 \\
\hline 8 & $1140 \pm 35.9$ & $1085 \pm 34.7 *$ & $1160 \pm 23.2$ & $1135 \pm 29.5$ & 0.000 \\
\hline 15 & $1292 \pm 38.8$ & $1180 \pm 34.8^{*}$ & $1250 \pm 21.1 *$ & $1173 \pm 27.1^{*}$ & 0.000 \\
\hline 22 & $1350 \pm 35.9$ & $1243 \pm 22.6^{*}$ & $1310 \pm 21.1 *$ & $1255 \pm 26.8^{*}$ & 0.000 \\
\hline 29 & $1370 \pm 34.0$ & $1310 \pm 21.1^{*}$ & $1350 \pm 21,1 *$ & $1245 \pm 25,5^{*}$ & 0.000 \\
\hline 36 & $1390 \pm 34.0$ & $1320 \pm 14.1^{*}$ & $1350 \pm 21.1 *$ & $1245 \pm 23.7 *$ & 0.000 \\
\hline 43 & $1395 \pm 30.3$ & $1315 \pm 15.8^{*}$ & $1350 \pm 21.1 *$ & $1240 \pm 24.9^{*}$ & 0.000 \\
\hline 50 & $1420 \pm 34.7$ & $1370 \pm 14.9^{*}$ & $1340 \pm 21.1 *$ & $1220 \pm 23.6^{*}$ & 0.000 \\
\hline 57 & $1420 \pm 33.3$ & $1400 \pm 20.6$ & $1320 \pm 20.0 *$ & $1280 \pm 23.6^{*}$ & 0.000 \\
\hline 64 & $1440 \pm 32.7$ & $1420 \pm 34.3$ & $1340 \pm 20.0 *$ & $1310 \pm 23.6^{*}$ & 0.000 \\
\hline 71 & $1460 \pm 32.7$ & $1430 \pm 34.3$ & $1340 \pm 20.0 *$ & $1330 \pm 23.6^{*}$ & 0.000 \\
\hline
\end{tabular}

Various concentrations of CY mixed in mustard oil were injected intraperitoneal to the male rabbits $(\mathrm{n}=10 \mathrm{x} 4)$ at weekly intervals. The values (mean $\pm \mathrm{SD})$ bearing asterisk in a row differ significantly $(\mathrm{P} \leq 0.05)$.

Table 4: Relative brain weight in $10^{3} \mathrm{ppm}$ in male rabbits treated with various cypermethrin doses

\begin{tabular}{|c|c|c|c|c|c|}
\hline \multirow[b]{2}{*}{ Experimental day } & \multicolumn{4}{|c|}{ Groups (CY dose: $\left.\mathrm{mg} \cdot \mathrm{kg}^{-1} \mathrm{bwt}\right)$} & \multirow[b]{2}{*}{ P-Value } \\
\hline & $\mathrm{W}(0)$ & $\mathrm{X}(50)$ & $\mathrm{Y}(100)$ & $\mathrm{Z}(150)$ & \\
\hline 15 & $6.93 \pm 0.39$ & $5.83 \pm 1.15$ & $5.88 \pm 0.22$ & $5.22 \pm 0.53$ & 0.225 \\
\hline 29 & $7.29 \pm 1.37$ & $5.77 \pm 0.49$ & $5.09 \pm 0.47$ & $5.98 \pm 0.53$ & 0.189 \\
\hline 43 & $4.75 \pm 0.03$ & $4.42 \pm 0.04$ & $4.18 \pm 0.11^{*}$ & $4.74 \pm 0.16$ & 0.012 \\
\hline 57 & $4.85 \pm 0.04$ & $4.46 \pm 0.04 *$ & $4.46 \pm 0.06^{*}$ & $4.45 \pm 0.08 *$ & 0.005 \\
\hline 71 & $4.71 \pm 0.24$ & $4.60 \pm 0.01$ & $4.55 \pm 0.11$ & $4.65 \pm 0.38$ & 0.909 \\
\hline
\end{tabular}

Various concentrations of CY mixed in mustard oil were injected intraperitoneal to the male rabbits $(\mathrm{n}=10 \mathrm{x} 4)$ at weekly intervals. Two rabbits from each group were euthanized fortnightly and the animals and their brains were weighed to calculate relative brain weight. The values (mean $\pm \mathrm{SD})$ bearing asterisk in a row differ significantly $(\mathrm{P} \leq 0.05)$. 
Int J Vet Sci, 2021, 10(4): 347-354.
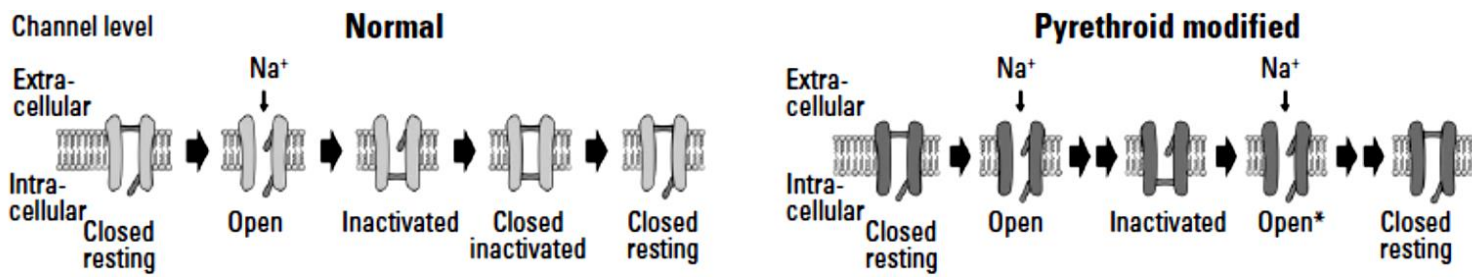

Fig. 4: Structure of voltage-gated sodium channels (VGSCs). a: Normal depolarization opens VGSCs and sodium enters the cell. To limit sodium entry and depolarization length, VGSCs inactivate and must return to a "resting" state before reopening. b: Pyrethroidmodified structure of VGSCs. Pyrethroids delay the inactivation of VGSCs (indicated by double arrows) and allow continued Na+ flux (Open*) (Shafer et al. 2005).

Table 5: The frequency and incidence of histological alterations in the brain of male rabbits treated with different cypermethrin doses

\begin{tabular}{|c|c|c|c|c|c|c|c|c|c|c|c|}
\hline \multirow[t]{3}{*}{ Histology alteration } & \multirow{3}{*}{$\begin{array}{l}\text { Groups/ } \\
\text { Dose }\left(\mathrm{mg} \cdot \mathrm{kg}^{-1}\right)\end{array}$} & \multicolumn{10}{|c|}{ Experimental days } \\
\hline & & \multicolumn{2}{|l|}{15} & \multicolumn{2}{|l|}{29} & \multicolumn{2}{|l|}{43} & \multicolumn{2}{|l|}{57} & \multicolumn{2}{|l|}{71} \\
\hline & & $\mathrm{F}^{*}$ & $\mathrm{I}^{* *}$ & $\mathrm{~F}$ & $\mathrm{I}$ & $\mathrm{F}$ & $\mathrm{I}$ & $\mathrm{F}$ & I & $\mathrm{F}$ & I \\
\hline \multirow{3}{*}{ Cerebellar hemorrhage } & $X(50)$ & ---- & 0 & ---- & 0 & ---- & 0 & +-- & 50 & +--- & 50 \\
\hline & $Y(100)$ & ---- & 0 & ---- & 0 & +--- & 50 & +-- & 50 & ++-- & 50 \\
\hline & $\mathrm{Z}(150)$ & ++- & 50 & ++- & 50 & ++- & 100 & +++- & 100 & ++++ & 100 \\
\hline \multirow[t]{3}{*}{ Immature pyramidal neurons } & $X(50)$ & +--- & 50 & +--- & 50 & +--- & 50 & +--- & 100 & ++-- & 100 \\
\hline & Y (100) & +--- & 50 & +--- & 50 & +--- & 100 & ++-- & 100 & ++-- & 100 \\
\hline & $Z(150)$ & +-- & 50 & +-- & 100 & ++-- & 100 & ++-- & 100 & +++- & 100 \\
\hline \multirow[t]{3}{*}{ Immature Purkinje cells } & $X(50)$ & --- & 0 & --- & 0 & +-- & 50 & ++- & 50 & ++- & 50 \\
\hline & $\mathrm{Y}(100)$ & +--- & 50 & ++- & 50 & ++- & 100 & ++-- & 100 & +++- & 100 \\
\hline & $\mathrm{Z}(150)$ & +--- & 50 & ++- & 50 & +++- & 100 & +++- & 100 & ++++ & 100 \\
\hline
\end{tabular}

$* \mathrm{~F}=$ Frequency; $* * \mathrm{I}=$ Incidence $(\%)$. Various concentrations of cypermethrin mixed in mustard oil were injected intraperitoneal to male rabbits $(n=10 \times 4=40)$ at weekly intervals. Two rabbits from each group were euthanized fortnightly. Tissue samples of the brain were preserved and processed to prepare histological slides and lesions in each group were scored based on severity (---- to ++++). The control group (W) did not show any alterations.

signs were skin irritation, coarse tremors, dullness, lacrimation, low body temperature, dilated pupils, increased eyeball movement, breathlessness, pawing, burrowing and ptyalism. Similarly, the decrease in average fodder intake was dose dependent. The above-mentioned stimulatory and excitatory modifications and variable sequence of motor signs in CY-treated rabbits suggested neurotoxicity (Khan et al. 2009).

Due to being lipophilic, pyrethroids come in the systemic circulation, cross the blood-brain barrier and interfere with the sodium channels in the nerve membrane (Sallam et al. 2015). They principally induce repetitive activity, particularly in the sensory nerves in the vertebrate (Shafer et al. 2005). The key approach of this action in insects, birds, fish, and mammals is the interruption in the voltage-gated sodium channel (VGSC) role. Axon membrane has VGSC that enables membrane polarity reversal and regenerative conduction (Sallam et al. 2015). Pyrethroids slow the activation or opening of VGSCs (Fig. 4). Repeated doses of CY lead to prolongation of sodium permeability of nerve membrane, thus associated with excitation, instead of transient increase (Igho and Afoke 2014). Such changes in VGSCs could be responsible for different brain alterations. Furthermore, pyrethroids deliberate the level of VGSC inactivation (or finishing) and move the membrane potential to further hyperpolarized potentials at which VGSCs trigger or open. Consequently, VGSCs trigger at further hyperpolarized potentials, and VGSCs stay open for a longer duration, permitting more sodium ions to pass through and depolarize the neuronal membrane. In general, type II pyrethroids (e.g., CY) interrupt the inactivation of VGSCs markedly longer than type I pyrethroids (e.g., permethrin). Type I pyrethroids just extend the VGSCs opening for a certain period that causes the repetitious firing of action potentials (repetitive discharge), however, type II pyrethroids keep the channels exposed and opened for a longer interval, depolarizing the membrane potential to a point at which generation of action potentials is not possible (Shafer et al. 2005; Sallam et al 2015). The CY causes delayed closure of VGSCs, thus increasing neuronal plasma membrane excitability due to a rapid increase in sodium influx. Generation of an action potential by membrane depolarization is responsible for the above neurological signs.

Moreover, the membrane of terminal branches and synaptic boutons (axon terminals) has voltage-gated calcium channels and membrane-associated receptors for uptake of released neurotransmitters. Calcium is involved in the release of neurotransmitter molecules and synaptic transmission (Eurell and Frappier 2006). The CY induces neurotoxicity through potassium channels, as well. Antagonism of the action of the pyrethroid with chloride channels at peripheral nerves could be responsible for ptyalism and those at CNS could be responsible for the motor signs of intoxication. Glutamate receptors are the most prevalent excitatory neurotransmitter in the brain, and they mediate almost all excitatory communications between CNS neurons (Shafer et al. 2005). Epileptic seizures are a problem of over-excitation of brain neurons; glutamate synapses are the main driving factor for them (Eurell and Frappier 2006). Therefore, CY causes neurotoxicity by hampering multifaceted levels of brain mechanism.

In the present study, the body weights were significantly $(\mathrm{P} \leq 0.05)$ decreased in animals treated with medium (100mg. $\mathrm{kg}^{-1} \mathrm{bwt}$ ) and high doses (150mg. $\mathrm{kg}^{-1}$ bwt) of CY at 15-71 days of observation. Reduced body weight might be due to weakened growth and metabolic 
irregularities including anemia (Ahmad et al. 2017). The trend of recovery of body weight in the low dose $(50 \mathrm{mg} . \mathrm{kg}$ ${ }^{1}$ bwt) group after 50 days could be due to metabolic adaptation after the $\mathrm{CY}$ dose is over. Numerous factors may lead to weight regain such behavioral interventions, including increased feed intake, compensatory growth, energy metabolism, endocrine function, and neural mechanisms (Brecchia et al. 2006).

Brains relative weight was significantly $(\mathrm{P} \leq 0.05)$ decreased in all treated groups at day 57 of observation, while in group $\mathrm{Y}$ that treated with medium dose (100 mg. $\mathrm{kg}^{-1}$ bwt) at day 43 . The decrease in the relative brains weights was similar to previous studies used pyrethroidtreatment (Sayim et al. 2005; Shafer et al. 2005), while other study showed opposite results (El-Shemi and El-Ella 2015). These discrepancies might be due to several reasons such as the health of the animals, previous exposure to CY, or any other insecticide (Ahmad et al. 2015). Conclusions from various toxicity studies might not constantly be repeatable unless all variables were aptly standardized (Aboelhadid et al. 2016). The CY accretion may cause brain damage and consequently loss of its weight. The CY toxicity-induce inhibition of acetylcholinesterase, the key enzyme in nerve conduction, is faster in the brain than other tissues. Thus pyrethroids are concentrated in the brain tissues as compared to other tissues (Zhang et al. 2017; Rodríguez et al. 2018).

Endoplasmic reticulum stress is strongly linked with cognitive dysfunction. Some researchers have linked repeated exposure to pyrethroids with learning inappropriateness through ER disturbance, apoptotic type of cell death in the hippocampus, and insufficiencies in hippocampal precursor production (Hossain et al. 2014). A decrease in brain potassium and magnesium adenosine triphosphatase (ATPase) in pyrethroid-exposed animals has been reported (El-Shemi and El-Ella 2015). Brain ATPase is a key enzyme in cellular water balance and osmoregulation. Lipophilic partitioning of ATPase by pyrethroids may produce allosteric change resulting in decreased ATPase activity (Rodríguez et al. 2018). The above-mentioned mechanisms may be the causes of decreasing relative brains weights in this study.

\section{Histological Alterations}

In the present study, the histopathological findings in the brains of the treated rabbits are in concurrence with those reported earlier in rats (Latuszynska et al. 2003; Sayim et al. 2005). The histological findings included different stages of neuronal degenerated pyramidal neurons of the cerebral cortex and degeneration of Purkinje neurons of the cerebellum. The cerebellum has an essential function in regulating voluntary movement and adjusting muscle tone with maintaining balance. Signs of cerebellar lesions include motor incoordination, ataxia, jerky or abnormal motions, tremors, disturbances of gait and balance, slurred speech, and oculomotor defects (Bodranghien et al. 2016). Toxicity can modify the pro-oxidant and antioxidant balance of cells causing inflammation as well as peripheral nerves and bone marrow perturbation (Khaki et al. 2017; Atere et al. 2019; Pardo et al. 2020).

The male rabbits were about 9 months of age at the end of this study. The majority of neurons complete their development at the pre-natal stage, thereafter several spare neurons degenerate. Neuronal stem cells, which are persevered mostly in a state of dormancy after birth, can restart dividing at any time of life. Consequently, the production of new neuronal cells may revitalize via bodily movement, exercise, or annexations. In young mice, the stem cells divide four times more frequently than in older animals (Lugert et al. 2010). Therefore, in the present study, CY-treated young rabbits showed different stages of neuronal development as a result of reactivation due to nervous signs.

Neurotoxicity of pyrethroids was severe at the early age, while in adults, it was mainly acute excitation. This effect of pyrethroid is reversible in 7 days. The pyrethroids not only induce setback of conduction block by demyelinated axons but also cause regenerative activity in un-lesioned cells. This result may reinforce pyrethroids recognized neurotoxic activities and rigorously limit their proven future (Askin et al. 2010). DNA damage has been an important lesion reported in pyrethroid genotoxicity studies (Ghaffar et al. 2015). Some pediatric toxicologists have found that exposure to deltamethrin (12.5mg. $\mathrm{kg}^{-1}$ ) alters perception, training, and recollection abilities in rat's progeny, along with obvious histological alterations in the cerebellar cortex of dams and their next-generation (ElBeltagy et al. 2019). Chlorpyrifos and CY mixture in rats produced focal pyknosis in the cortex of cerebri and cerebellum along with the focal concentration of the cytoplasm of the neurocytes in the stratum granulosum, hypothalamus, and cortex cerebrum (Latuszynska et al. 2003; Cao et al. 2015). Exposure of CY in many sprayworkers produced alteration of the Purkinje cells in the cerebellum and with the drawl of the CY, exposure leads to the disappearance of lesions. Many aspects of developmental neurotoxicity have been associated with environmental exposures. Due to such deleterious changes in behavior as well as in tissues, people have the tendency to consume organ foods escaping the adverse side effects of the chemicals (Aboelhadid et al. 2016).

Sex-associated aspects of CY neurotoxicity need a special focus. The CY could decrease sperm cells count in testes and steroidogenesis-related genes in Leydig cells (Ahmad et al. 2012). The CY did not affect gonadotropinreleasing hormone $(\mathrm{GnRH})$ gene expression in hypothalamus but stimulated GnRH pulse frequency (Ye et al. 2017). Moreover, CY could induce the secretion of luteinizing and follicle-stimulating hormones and the expression of $\mathrm{Gn}$-subunit genes in pituitary gonadotropins (Ye and Liu 2019). A limitation of the present study is the use of male rabbits only as some parameters have been reported to show sex-dependent responses in CY-treated animals (Ahmad et al. 2017).

The mechanism of action of pyrethroids includes the delaying closure of voltage-sensitive sodium and chloride channels. These compounds are neurotoxic. Studies have shown that they cause many immune disorders contributing to the lowering of immunity in humans and animals (Skolarczyk et al. 2017). Exposure to pyrethroids can cause inhibition of proliferation of peripheral blood leukocytes and reducing the concentration of IgG (Hołyńska-Iwan and Szewczyk-Golec 2020) thus exposure to CY could predispose the animals/humans to infections especially viral infections. 


\section{Conclusion}

From the results of this study, it was concluded that $\mathrm{CY}$ at (100 and $150 \mathrm{mg} \cdot \mathrm{kg}^{-1} \mathrm{bwt}$ ) or its environmental accumulation could lead to brain and behavior alterations in rabbits and reduction in lifespan and/or quality of life through impairing normal neuronal conduction. As explained earlier that exposure to pyrethroids may lead to peripheral blood leukocytes proliferation inhibition and decreased concentration of IgG. Thus, CY exposed animals/humans could be prone to infections especially the viral type of infection.

\section{Authors' Contributions}

LA and AK conceived and designed the project and study. LA, STG, AUR, and MKS executed the experiment and analyzed the clinical signs and tissue samples. LA, AK, SNHN, and RH analyzed the data. The manuscript was drafted by LA, AK and XXD. All authors interpreted the data, critically revised the manuscript for important intellectual contents, and approved the final version.

\section{Declaration of Competing Interest}

The authors declare that they have no known competing financial interests or personal relationships that could have appeared to influence the work reported in this paper.

\section{Acknowledgment}

This work was supported by HEC Grant (PIN code MLA 0543318). The authors are thankful to M/S Ali Akbar Group of Companies, Pakistan for donating Cypermethrin (92\% technical grade) for this experimental work.

\section{REFERENCES}

Aboelhadid SM, Mahrous LN, Hashem SA, Abdel-Kafy E-SM and Miller RJ, 2016. In vitro and in vivo effect of Citrus limon essential oil against sarcoptic mange in rabbits. Parasitological Research 115: 3013-3020. https://doi.org/ 10.1007/s00436-016-5056-8

Ahmad L, Khan A, Khan MZ, Hussain I, Mahmood F, Sleemi MK, Lodhi LA and Abdullah I, 2012. Toxico-pathological effects of cypermethrin upon male reproductive system in rabbits. Pesticide Biochemistry and Physiology 103: 194201. http://dx.doi.org/10.1016/j.pestbp.2012.05.004

Ahmad L, Khan A, Rind MI, Vistro WA, Raza MA, Khawaja T, Tabassum T, Hussain I, Hussain K, Shahani S, Leghari MF and Javed MT, 2017. Cypermethrin-induced repeated-dose immuno-toxicity in Oryctolagus Cuniculus: An investigation into pathology of spleen and blood. International Archives of BioMedical and Clinical Research 3: 40-45. https://doi.org/10.21276/iabcr.2017.3.2.x

Ahmad MZ, Khan A, Javed MT and Hussain I, 2015. Impact of chlorpyrifos on health biomarkers of broiler chicks. Pesticide Biochemistry and Physiology 122: 50-58. http://doi.org/ 10.1016/j.pestbp.2014.12.024

Akram R, Ghaffar A, Hussain R, Khan I, Santana VLDA, Mehmood K, Naz S, Iqbal R, Imran HM, Qamar MR and Zhu $\mathrm{H}$, 2021. Hematological, serum biochemistry, histopathological and mutagenic impacts of triclosan on fish (bighead carp). Agrobiological Records. https://doi.org/ 10.47278/journal.abr/2021.009

Amaral AFS, 2014. Pesticides and asthma: Challenges for epidemiology. Frontiers in Public Health 2: 6. https://doi.org/10.3389/fpubh.2014.00006
Askın A, Çömelekoğlu U, Yılmaz BC, Yalın S, Aktaş S, Mazmancı B, Çamlıca Y and Çelik A, 2010. Neurotoxic actions of lambda-cyhalothrin on rat sciatic nerve. Fresenius Environmental Bulletin 19: 100-107.

Atere AD, Oseni BSA, Agbona TO, Idomeh FA, Akinbo DB and Osadolor HB, 2019. Free radicals inhibit the haematopoietic elements and antioxidant agents of rats exposed to pyrethroids insecticide. Journal of Experimental Research 7: 66-74.

Bodranghien F, Bastian A, Casali C, Hallett M, Louis E, Manto M, Mariën P, Nowak DA, Schmahmann JD, Serrao M, Steiner KM, Strupp M, Tilikete C, Timmann D and van Dun K, 2016. Consensus paper. Revisiting the symptoms and signs of cerebellar syndrome. Cerebellum 15: 369-391. doi:10.1007/s12311-015-0687-3

Brecchia G, Bonanno A, Galeati G, Federici G, Maranesi M, Gobbetti A, Zerani M and Boiti C, 2006. Hormonal and metabolic adaptation to fasting effects on the hypothalamicpituitary-ovarian axis and reproductive performance of rabbit does. Domestic Animals Endocrinology 31: 105-122. 10.1016/j.domaniend.2005.09.006

Cao D, Chen N, Zhu C, Zhao Y, Liu L, Yang J and An L, 2015. $\beta$-cypermethrin-induced acute neurotoxicity in the cerebral cortex of mice. Drug and Chemical Toxicology 38: 44-49. https://doi.org/10.3109/01480545.2014.900072

Ecobichon DJ, 1996. Toxic effects of pesticides. In: "Casarett and Doull's Toxicology: The Basic Science of Poisons". (C. Klassen Ed.), Macmillan, New York, pp: 677.

El-Beltagy AEBM, Elbakry KAM, Elghazaly MMA, Ali LS and EL Daqaqq NHM, 2019. Adverse effects of deltamethrin on the cerebellum of mothers rats and their offspring and the possible ameliorative role of melatonin. International Journal of Pure and Applied Zoology 7: 55-74.

El-Shemi AG and El-Ella GAA, 2015. Hepatic and neural toxicity and tissue residue of cypermethrin in male Somali sheep (Berbera blackhead). Assiut Veterinary Medicine Journal 61: 52-59.

Eurell JA and Frappier BL, 2006. Nervous Tissue ( $6^{\text {th }}$ Chapter). Dellmann's Textbook of Veterinary Histology. $7^{\text {th }}$ Ed. Blackwell Publishing, Ames, Iowa, USA.

Garrigou A, Laurent C, Berthet A, Colosio C, Jas N, DaubasLetourneux V, Filho J-MJ. Jouzel J-N, Samuel O, Baldi I, Lebailly P, Galey L, Goutille F and Judon N, 2020. Critical review of the role of PPE in the prevention of risks related to agricultural pesticide use. Safety Science 123: 104527. https://doi.org/10.1016/j.ssci.2019.104527

Ghaffar A, Hussain R, Khan A and Abbas RZ, 2015. Hematobiochemical and genetic damage caused by triazophos in fresh water fish, Labeo rohita. International Journal of Agriculture and Biology 17: 637-642.

Ghaffar A, Hussain R, Noreen S, Abbas G, Chodhary IR, Khan A, Ahmed Z, Khan MK, Akram K, Ulhaq M, Ahmad N, Ali $\mathrm{F}$ and Niaz M, 2020. Dose and time-related pathological and genotoxic studies on thiamethoxam in fresh water fish (Labeo rohita) in Pakistan. Pakistan Veterinary Journal 40: 151-156. http://doi.org/10.29261/pakvetj/2020.002

Gul ST, Ahamd I, Saleemi MK, Ahmad M, Ahmad L and Khan A, 2020. Toxico-pathological effects of thiamethoxam on hemato-biochemical and productive performance of commercial laying hens. Pakistan Veterinary Journal 40: 449-454. http://doi.org/10.29261/pakvetj/2020.052

Gupta A, 2012. Pesticide Residues in Food Commodities: Advances in Analysis, Evaluation, and Management, with Parti by Gupta”, Agrobios. Jodhpur-342003, India

Hartley D and Kidd H, 1990. The Agrochemicals Handbook. $2^{\text {nd }}$ Ed. Royal Society of Chemistry, Cambridge, UK.

Hegab AA, Fahmy MM, Omar HM, Abuowarda MM and Gattas SG, 2020. Investigation of tickborne pathogens within naturally infected brown dog tick (ixodidae: Rhipicephalus Sanguineus) in Egypt by light and electron microscopy. 
International Journal of Veterinary Science 9: 476-482. https://doi.org/10.37422/IJVS/20.064

Hołyńska-Iwan I and Szewczyk-Golec K, 2020. Pyrethroids: How they affect human and animal health? Medicina (Kaunas) 56: 582. https://doi.org/10.3390/medicina56110582

Hossain MM, Bloom EDC and Richardson JR, 2014. Hippocampal ER stress and learning deficits following repeated pyrethroid exposure. Toxicological Sciences 143: 220-228. http://doi.org/10.1093/toxsci/kfu226

Igho OE and Afoke IK, 2014. A histomorphologic analysis of pyrethroid pesticide on the cerebrum and cerebellum of adult albino rats. Journal of Experimental and Clinical Anatomy 13: 54-59. http://doi.org/10.4103/1596-2393.154401

Khaki A, Khaki AA and Rajabzadeh A, 2017. The effects of permethrin and antioxidant properties of Allium cepa (onion) on testicles parameters of male rats. Toxin Reviews 36: 1-6. http://doi.org/10.1080/15569543.2016.1235582

Khan A, Faridi HAM, Ali M, Khan MZ, Siddique M, Hussain I and Ahmad M, 2009. Effects of cypermethrin on some clinico-hemato-biochemical and pathological parameters in male dwarf goats (Capra hircus). Experimental and Toxicologic Pathology 61: 151-160. http://doi.org/10.1016/ j.etp.2008.07.001.

Kim KH, Kabir E and Jahan SA, 2017. Exposure to pesticides and the associated human health effects. Science of Total Environment 575: 525-535. https://doi.org/10.1016/j. scitotenv.2016.09.009

Latuszynska J, Luty S, Raszewski G, Przebirowska D and Tokarska-Rodak M, 2003. Neurotoxic effect of dermally applied chlorpyrifos and cypermethrin-reversibility of changes. Annals of Agricultural and Environmental Medicine 10: 197-201.

Lugert S, Basak O, Knuckles P, Haussler U, Fabel K, Gotz M, Haas CA, Kempermann G, Taylor V and Giachino C, 2010. Quiescent and active hippocampal neural stem cells with distinct morphologies respond selectively to physiological and pathological stimuli and ageing. Cell Stem Cell 6: 445456. https://doi.org/10.1016/j.stem.2010.03.017

Mnif W, Hassine AIH, Bouaziz A, Bartegi A, Thomas O and Roig B, 2011. Effect of endocrine disruptor pesticides: A review. International Journal of Environmental Research and Public Health 8: 2265-2303. https://doi.org/10.3390/ijerph8062265

Mujahid Q, Khan A, Qadir MF, Ahmad A, Ejaz W, Mujahid S, Mujahid J, Khalid S, Chohan TZ, Saleemi MK and Badar M, 2021. Allethrin induced toxicopathological alterations in adult male albino rats. Agrobiological Records 5: 8-14. https://doi.org/10.47278/journal.abr/2020.019

Nielsen VG, Sanchez EE and Redford DT, 2018. Characterization of the rabbit as an invitro and in vivo model to assess the effects of fibrinogenolytic activity of snake venom on coagulation. Basic and Clinical Pharmacology and Toxicology 122: 157-164. https://doi.org/10.1111/bcpt.12848

Özkara A, Aky1l D and Konuk M, 2016. Pesticides, Environmental Pollution, and Health. IntechOpen Limited, London, UK. https://doi.org/10.5772/63094

Pardo ID, Rao DB, Morrison JP, Huddleston C, Bradley AE, Bolon B and Garman RH, 2020. Nervous system sampling for general toxicity and neurotoxicity studies in rabbits. Toxicologic Pathology 48: 810-826. https://doi.org/10.1177/ 0192623320957637

Percie du Sert N, Ahluwalia A, Alam S, Brown WJ, Steckler T and Würbel H, 2020. The ARRIVE guidelines 2.0: Updated guidelines for reporting animal research. PLoS Biology 18: e3000410. https://doi.org/10.1371/journal.pbio.3000410

Rajawat NK, Soni I, Syed F, Verma R, John PJ and Mathur R, 2019. Effect of $\beta$-cyfluthrin (synthetic pyrethroid) on learning, muscular coordination and oxidative stress in Swiss albino mice. Toxicology and Industrial Health 35: 358-367. https://doi.org/10.1177/0748233719840957

Ren Z, Poopal RK and Ramesh M, 2021. Synthetic organic chemicals (flame retardants and pesticides) with neurotoxic potential induced behavioral impairment on zebrafish (Danio rerio): a non-invasive approach for neurotoxicology. Environmental Science and Pollution Research 28: 37534 37546. https://doi.org/10.1007/s11356-021-13370-2

Rodríguez JL, Ares I, Martinez M, Martinez-Larrañaga MR and Anadón A, 2018. Bioavailability and nervous tissue distribution of pyrethroid insecticide cyfluthrin in rats. Food Chemistry and Toxicology 118: 220-226. http://doi.org/ 10.1016/j.fct.2018.05.012

Sallam MA, M Ahmad, I Ahmad, ST Gul, M Idrees, MI Bashir and M Zubair, 2015. Toxic effects of cypermethrin on the reproductive functions of female rabbits and their amelioration with vitamin $\mathrm{E}$ and selenium. Pakistan Veterinary Journal 35: 193-196.

Sayim F, Yavasolglu NUK, Uyanikgil Y, Aktug H, Yavasolglu A and Turgut M, 2005. Neurotoxic effects of cypermethrin in Wistar rats: a hematological, biochemical and histopathological study. Journal of Health Sciences 51: 300-307.

Shafer TJ, Meyer DA and Crofton KM, 2005. Developmental neurotoxicity of pyrethroids: Critical review and future research needs. Environmental Health and Perspectives 113: 123-136. http://doi.org/10.1289/ehp.7254

Skolarczyk J, Pekar J and Nieradko-Iwanicka B, 2017. Immune disorders induced by exposure to pyrethroid insecticides. Postepy Higieny i Medycyny Doswiadczalnej (Online) 71: 446-453. https://doi.org/10.5604/01.3001. $\underline{0010.3827}$

Suvarna KS, Layton C and Bancroft JD, 2018. Bancroft's Theory and Practice of Histological Techniques. $8^{\text {th }}$ Ed. Elsevier Limited

Tahir R, Ghaffar A, Abbas G, Turabi TH, Kausar S, Xiaoxia Du, Naz S, Jamil H, Samra, Riaz S and Abdelgayed SS, 2021. Pesticide induced hematological, biochemical and genotoxic changes in fish: A review. Agrobiological Records 3: 41-57. https://doi.org/10.47278/journal.abr/2021.005

Tudi M, Daniel Ruan H, Wang L, Lyu J, Sadler R, Connell D, Chu C and Phung DT, 2021. Agriculture development, pesticide application and its impact on the environment International Journal of Environmental Research and Public Health 18: 1112. https://doi.org/10.3390/ijerph18031112

Ye XQ and Liu J, 2019. Effects of pyrethroid insecticides on hypothalamic-pituitary-gonadal axis: a reproductive health perspective. Environmental Pollution 245: 590-599. https://doi.org/10.1016/j.envpol.2018.11.031

Ye XQ, Li F, Zhang J, Ma H, Ji D, Huang X, Curry Jr TE, Liu W and Liu J, 2017. Pyrethroid insecticide cypermethrin accelerates pubertal onset in male mice via disrupting hypothalamic-pituitary-gonadal axis. Environmental Science and Technology 51: 10212-10221. https://doi.org/ 10.1021/acs.est.7b02739

Zhang C, Sun Y, Hu R, Huang J, Huang X, Li Y, Yin Y and Chen ZA, 2018. Comparison of the effects of agricultural pesticide uses on peripheral nerve conduction in China. Scientific Reports 8: 9621. https://doi.org/10.1038/s41598-018-27713$\underline{6}$

Zhang T, Yang M, Pan H, Li S, Ren B, Ren Z, Xing N, Qi L, Ren Q, Xu S, Song J, and Ma J, 2017. Does time difference of the acetylcholinesterase (AChE) inhibition in different tissues exist? A case study of zebrafish (Daniorerio) exposed to cadmium chloride and deltamethrin. Chemosphere 168: 908 916. https://doi.org/10.1016/j.chemosphere.2016.10.119 